\title{
Impact Coefficient Analysis of Long-Span Railway Cable-Stayed Bridge Based on Coupled Vehicle-Bridge Vibration
}

\author{
Yongle Li, ${ }^{1}$ Shifu Dong, ${ }^{1,2}$ Yulong Bao, ${ }^{1}$ Kejian Chen, ${ }^{3}$ and Shizhong Qiang ${ }^{1}$ \\ ${ }^{1}$ Department of Bridge Engineering, Southwest Jiaotong University, Chengdu 610031, China \\ ${ }^{2}$ Hubei Provincial Communication Planning and Design Institute, Wuhan 430051, China \\ ${ }^{3}$ China Railway Eryuan Engineering Group Co., Ltd., Chengdu 610031, China \\ Correspondence should be addressed to Yongle Li; lele@swjtu.edu.cn
}

Received 9 August 2014; Accepted 17 October 2014

Academic Editor: Ting-Hua Yi

Copyright (C) 2015 Yongle Li et al. This is an open access article distributed under the Creative Commons Attribution License, which permits unrestricted use, distribution, and reproduction in any medium, provided the original work is properly cited.

\begin{abstract}
Compared with medium and small span bridges, very limited attention has been paid on the research of the impact coefficient of long-span railway bridges. To estimate the impact effects of long-span railway bridges subjected to moving vehicles, a real longspan railway cable-stayed bridge is regarded as the research object in this study, and a coupled model of vehicle-bridge system is established. The track irregularities are taken as the system excitation and the dynamic responses of the vehicle-bridge system are calculated. The impact effects on main girder, stayed cable, bearings, and bridge tower are discussed at various vehicle speeds. The results show that different components of the long-span railway cable-stayed bridge have different impact coefficients. Even for each part, the impact coefficient is also different at different local positions. It reveals that the impact coefficients in the actual situation may have significant differences with the related code clauses in the present design codes.
\end{abstract}

\section{Introduction}

Along with the all-round development of the railways in China, higher train speed, heavier axle load, and greater traffic density have brought out the issue of the dynamic interaction between vehicles and old long-span railway bridges. In addition, long-span railway bridges are also subjected to intensive environmental loadings due to the interaction with the environment conditions [1-3]. The traffic and environmental loading effects in bridges may induce the structural movement and stresses due to the indeterminacy, which may cause the damage events of the structural components even the entire bridge. Therefore, it is essential to understand the static and dynamic responses for the bridge performance assessment with the aids of the various monitoring sensors and techniques $[4,5]$. Among the crucial parameters of the bridge, the impact coefficient is commonly utilized for the performance evaluation of the long-span railway bridges. In the bridge design codes, the impact coefficient is defined as an increase factor of the static loads, which reflects the dynamic effects of the moving vehicles on bridges. The impact coefficient of the bridge, as the comprehensive reflection of the dynamic characteristics and interactions in the vehicletrack-bridge system, plays an important role in the health monitoring, safety assessment, and lifetime prediction for the bridges $[2,6]$. To ensure the health and reliability of old longspan railway bridges, it is of great significance to analyze the influence factors and rules of impact coefficient in the theory and engineering application [7-9].

Many researches to quantify the impact coefficient have been conducted by bridge engineers around the world. Matsuura studied the dynamic characteristics of high-speed railway bridges subjected to moving vehicles and indicated that the bridge resonance induced by the regular arrangement of axle load was significant [10]. Bhatti et al. studied the dynamic response of a simply supported truss bridge, which showed that each member bar of the truss had different local impact coefficients [11]. Song et al. investigated the dynamic 
amplification factors of a cable-stayed maglev bridges by idealizing the cable-stayed bridge as a simple beam on an elastic foundation [12]. Chen et al. studied the static, dynamic, and fatigue condition of long-span suspension bridges on the basis of structural health monitoring system (SHM) $[13,14]$.

Existing impact studies primarily focused on simply supported medium or small span bridges, while little attention has been paid on long-span railway cable-stayed bridges $[15,16]$. Compared with simply supported bridges, cablestayed bridge is featured as a flexible structure which can be considered as combined systems of main girder, stayed cable, tower, and pier. Each component of the cable-stayed bridge may have different impact coefficients. However, one bridge only has one specific value of impact coefficient according to the related codes of railway bridges in both China and abroad, which could not reflect the different impact effects on each component.

Coupled vehicle-bridge vibration is applied to analyze the impact effects in this study. To validate the reliability of the algorithm, this paper studies a $32 \mathrm{~m}$ simply supported bridge first. Then, a long-span railway cable-stayed bridge is investigated in order to evaluate the impact effects of each component. To some extent, numerical results from this study can serve as valuable reference to the design, construction, and maintenance of long-span railway bridges. Besides, to optimize sensor placement for structural health monitoring $[5,17]$, impact coefficients can be defined as "health index" to estimate the health and safety of bridges, which are available to identify the vulnerable parts of the bridge in the health monitoring process [18]. Furthermore, the coupled vehiclebridge vibration analysis could be regarded as a theoretical method to quantify the impact response of bridges in the vibration monitoring based on field testing.

\section{Modeling of Coupled Vehicle-Bridge System and Its Verification}

2.1. Modeling of Coupled Vehicle-Bridge Vibration System. Self-developed analysis software "Bridge Analysis System" (BANSYS) is employed to analyze the dynamic responses of the coupled vehicle-bridge system [19].

2.1.1. Modeling of Rail Vehicles. A train usually consists of bodies, wheelsets, bogies, and suspension systems, and all the locomotives and coaches can be modeled into mass-springdamper systems as shown in Figure 1 (e.g., a 4-axle vehicle). Considering the secondary suspension system for a four-axle vehicle, the whole vehicle can be divided into seven rigid bodies: one vehicle body, two bogies, and four wheelsets, and they are connected with each other by springs and dampers. In this study, it is assumed that the degree of freedom (DOF) along the traveling direction can be neglected. Thus, each vehicle body and bogies are specified with five DOFs in the lateral, vertical, floating, rolling, yawing, and nodding directions. The wheelset only has two independent DOFs in the lateral and yawing directions. That is to say, a four-axle vehicle has total 23 DOFs which can indicate the vibration characteristics of a railway vehicle well.
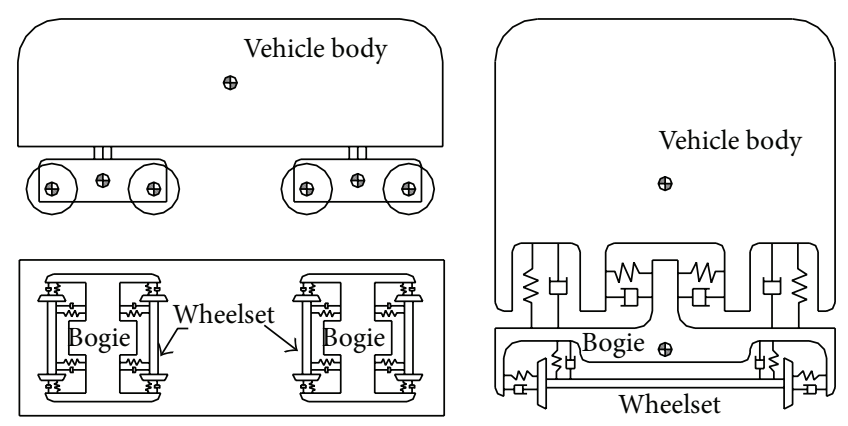

FIGURE 1: Mass-spring-damper model of vehicle.

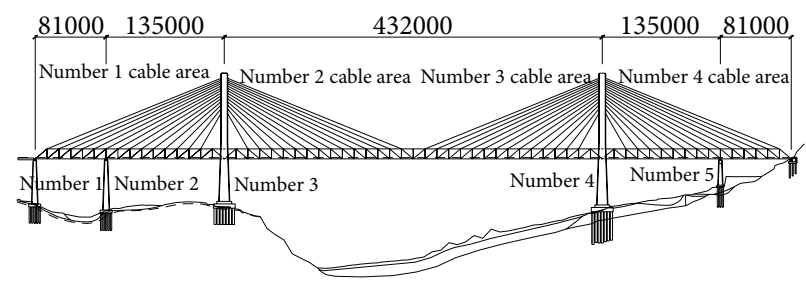

FIgURE 2: Overall arrangement of the cable-stayed bridge (units: millimeters).

2.1.2. Modeling of Hanjiatuo Bridge. Hanjiatuo Bridge shown in Figure 2 has a main span of 432 meters. It is a long-span railway cable-stayed bridge with steel truss deck, two towers, and double cable planes, which belongs to semifloating supported configuration.

A finite element model for the bridge is established using the general FEM software ANSYS. Beam4 is used to model the main girder and tower; Link8 is employed to model the stayed cable; and a three-orthogonal-beam model for the finite element is adopted to simulate the foundation stiffness [20]. The finite element model of the cable-stayed bridge is shown in Figure 3. The results of the dynamic characteristic analysis of the bridge model show that the first, second, and third order mode shapes are the longitudinal, transversal, and vertical bending, respectively. Their fundamental frequencies are $0.159 \mathrm{~Hz}, 0.287 \mathrm{~Hz}$, and $0.423 \mathrm{~Hz}$, respectively. The first ten natural frequencies and mode shapes are shown in Table 1.

2.2. Verification. Impact coefficient $[16,21]$ can be defined as amplification in the design traffic load resulting from the interaction of moving vehicles and bridges. The impact coefficient $\mu$ is defined as follows:

$$
\mu=\frac{\left(R_{d \max }-R_{s \max }\right)}{R_{s \max }},
$$

where $R_{d \text { max }}$ is the maximum dynamic response in the time history curve while $R_{s \max }$ is the maximum static response value in the time history curve.

In order to validate the reliability of the algorithm, the vertical vibration response of a $32 \mathrm{~m}$ simply supported bridge has been investigated $[22,23]$. Various vehicle speeds are discussed, and the numerical results are compared with those calculated by the impact formulas presented in the existing 


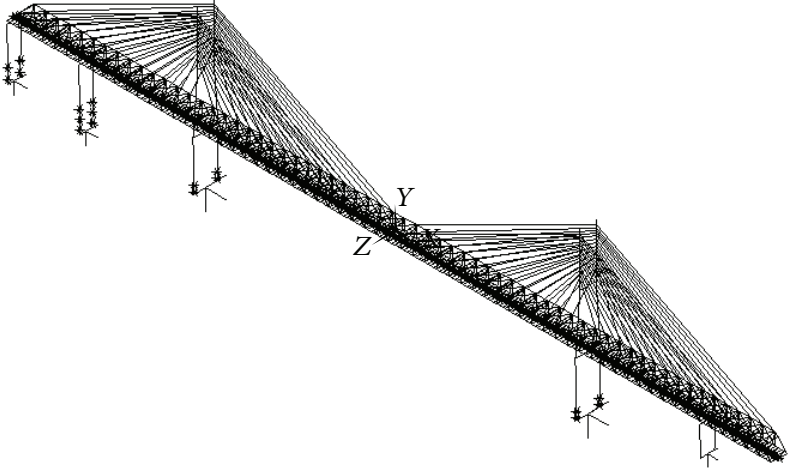

Figure 3: Finite element model of the cable-stayed bridge.

TABLE 1: Frequency and vibration shape of the bridge.

\begin{tabular}{|c|c|c|}
\hline Order & Frequency/Hz & Mode shape \\
\hline 1 & 0.15851 & $\begin{array}{l}\text { Main girder longitudinal } \\
\text { drifting }\end{array}$ \\
\hline 2 & 0.28670 & $\begin{array}{l}\text { Main girder lateral } \\
\text { symmetric bending-1 }\end{array}$ \\
\hline 3 & 0.42343 & $\begin{array}{l}\text { Main girder vertical } \\
\text { symmetric bending-1 }\end{array}$ \\
\hline 4 & 0.47667 & $\begin{array}{l}\text { Main girder lateral } \\
\text { antisymmetric bending-1 }\end{array}$ \\
\hline 5 & 0.49741 & $\begin{array}{l}\text { Main girder lateral } \\
\text { antisymmetric bending- } 2\end{array}$ \\
\hline 6 & 0.70407 & $\begin{array}{l}\text { Main girder lateral } \\
\text { antisymmetric bending-3 }\end{array}$ \\
\hline 7 & 0.71530 & $\begin{array}{l}\text { Main girder vertical } \\
\text { antisymmetric bending-1 }\end{array}$ \\
\hline 8 & 0.81917 & Tower lateral bending-1 \\
\hline 9 & 0.81918 & Tower lateral bending-2 \\
\hline 10 & 0.81973 & Pier longitudinal bending \\
\hline
\end{tabular}

codes. A simply supported bridge with eight spans is shown in Figure 4. It consists of four posttensioned precast simple T-beams.

When a train passes through the simply supported bridge at a constant velocity $V$, the arrangement of the train axle loads has certain regularity. The train axle load impacted on the bridge equals a cyclic loading with a frequency of $f_{v}\left(f_{v}=V / L_{v}\right)$. When the loading frequency $f_{v}$ and the natural frequency of bridge $f_{b}$ have a relation with integer times $i$, resonance will be excited on the bridge, and an impact coefficient peak will appear. The resonance speed [24] corresponding to the $i$ th bridge's resonance, (2), is defined as

$$
v_{i}=\frac{f_{b} \times L_{v}}{i} \quad(i=1,2,3, \ldots),
$$

where $f_{b}$ is the natural frequency of the bridge in $\mathrm{Hz}$; and $L_{v}$ is the length of the train in meters.

The eight-span simply supported bridge is established based on self-developed analysis software BANSYS. According to the calculation results, the natural frequency of the bridge is $3.864 \mathrm{~Hz}$. A CRH2 passenger train of $26 \mathrm{~m}$ length,

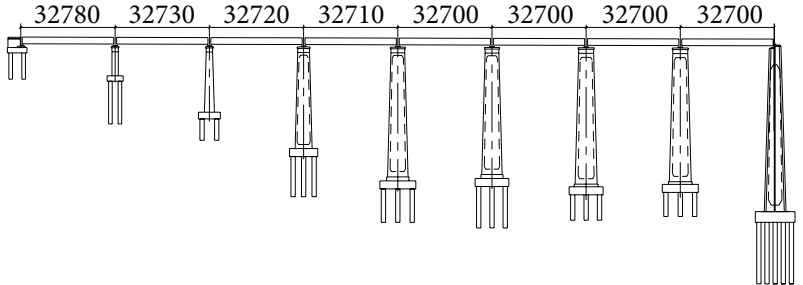

Figure 4: General elevation of a simple beam bridge (units: millimeters).

with a train arrangement of $2 \times(1$ trailer +1 motor +1 motor +1 trailer), is employed in this study to investigate the resonance speeds for the bridge, and some parameters of $\mathrm{CRH} 2$ are shown in Table 2. The results show that the first three theoretical resonance speeds corresponding to (2) are $361.7 \mathrm{~km} / \mathrm{h}, 180.8 \mathrm{~km} / \mathrm{h}$, and $120.3 \mathrm{~km} / \mathrm{h}$, respectively.

To study the vertical resonance response of the simply supported bridge at high speeds, the vehicle speed range is set from $100 \mathrm{~km} / \mathrm{h}$ to $420 \mathrm{~km} / \mathrm{h}$ with an interval of $10 \mathrm{~km} / \mathrm{h}$. The measured track irregularities of Zhengzhou-Wuhan line, as shown in Figure 5, are taken as the system excitation inputs. The dynamic response of the vehicle-bridge system and the static response of the bridge with moving loads passing through the bridge were obtained from BANSYS. Then the maximum dynamic and static responses can be obtained in the time history curves, and according to (1), the curves of the impact coefficients for the vertical displacement and bending moment of the 1st midspan at various vehicle speeds are calculated and shown in Figure 6.

As shown in Figure 6, the impact coefficient for the simply supported bridge does not increase monotonously with the vehicle speed, and some peak values appear in the curves. The peak values of the impact coefficient appear at the speed of $120 \mathrm{~km} / \mathrm{h}$ and $360 \mathrm{~km} / \mathrm{h}$, which is close to the third theoretical resonance speed $(120.6 \mathrm{~km} / \mathrm{h})$ and the first resonance speed $(361.7 \mathrm{~km} / \mathrm{h})$ of the bridge. The results show that it is feasible to quantify the impact coefficient with the method of the coupled vehicle-bridge vibration. Meanwhile, the reliability of analysis software BANSYS is validated.

Vibration cancellation phenomenon occurs at the second resonance speed $(180 \mathrm{~km} / \mathrm{h})$, which leads to the disappearance of resonance. When the train speed simultaneously satisfies conditions of both vibration cancellation and resonance phenomena, cancellation plays a predominant role, and the peak value of impact coefficient disappears [25]. In addition, the impact coefficients for the vertical displacement and bending moment are essentially consistent, and the impact coefficient for the vertical displacement will be studied at the most conditions in the following context.

The comparison of the impact coefficients quantified by the method of the coupled vehicle-bridge vibration with the values calculated by the impact formulas presented in the existing codes [26-29] is shown in Figure 7.

As shown in Figure 7, in the range of the design vehicle speed $(200 \mathrm{~km} / \mathrm{h}$ ) except for $120 \mathrm{~km} / \mathrm{h}$ (the third resonance speed), the impact coefficients obtained from the coupled 
TABLE 2: Weight and yawing inertia of CRH2.

\begin{tabular}{|c|c|c|c|c|c|c|}
\hline \multirow{2}{*}{ Vehicle type } & \multicolumn{3}{|c|}{ Weight/t } & \multicolumn{3}{|c|}{ Yawing inertia $/ \mathrm{t} \cdot \mathrm{m}^{2}$} \\
\hline & Body & Wheelset & Bogie & Body & Wheelset & Bogie \\
\hline Locomotive & 39.60 & 2.00 & 3.20 & 1900 & 0.980 & 3.20 \\
\hline Trailer & 34.10 & 2.10 & 2.60 & 1700 & 1.029 & 2.60 \\
\hline
\end{tabular}
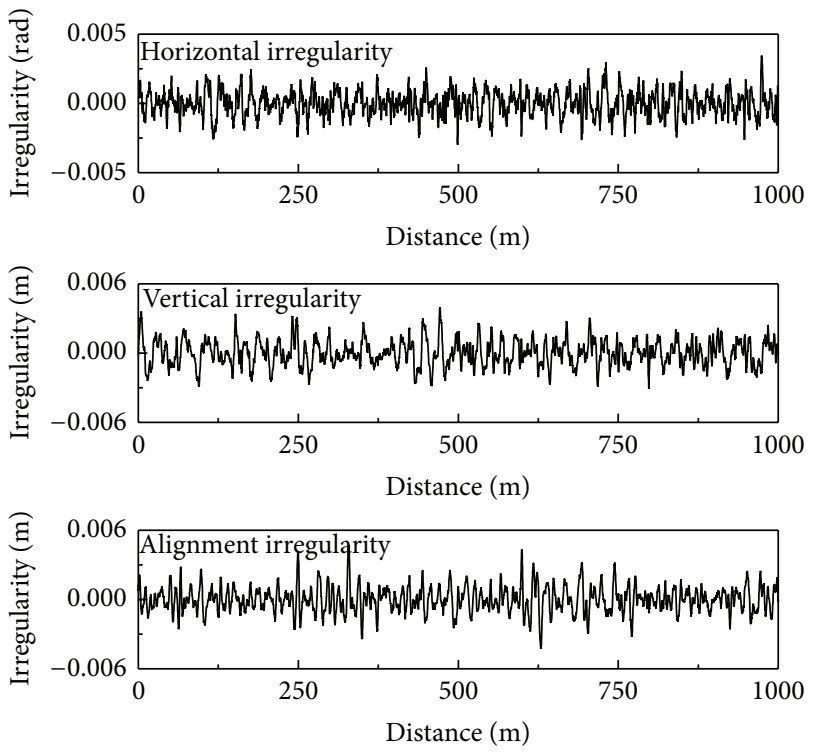

FIGURE 5: Track irregularities of Zhengzhou-Wuhan line.

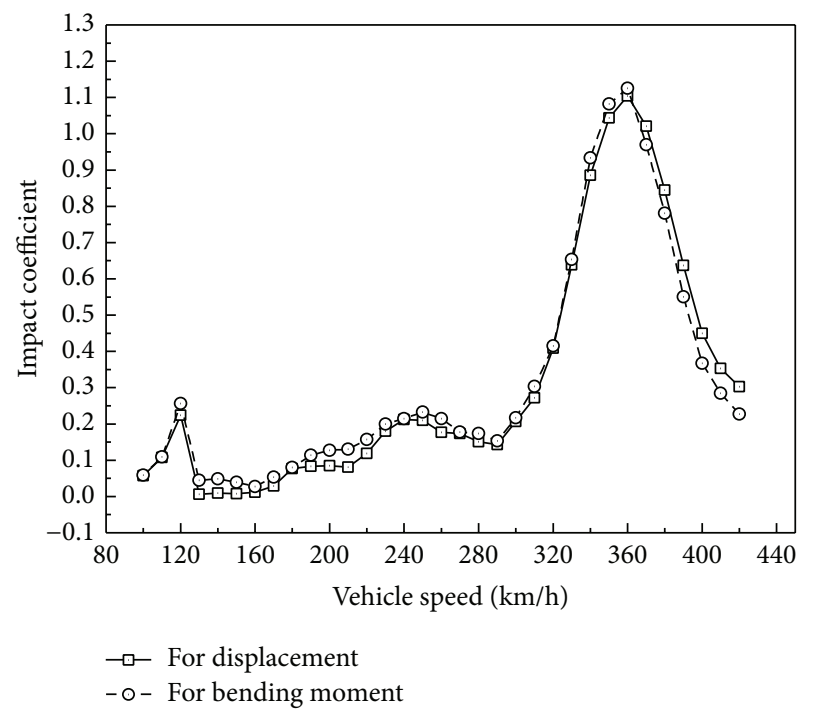

FIGURE 6: Impact coefficients of the 1st midspan.

vehicle-bridge system model satisfy the requirement of Fundamental Code for Design on Railway Bridge and Culvert [30]. And the impact coefficients calculated by the code formulas are greater than the numerical results quantified from the coupled vehicle-bridge model at most vehicle speeds.

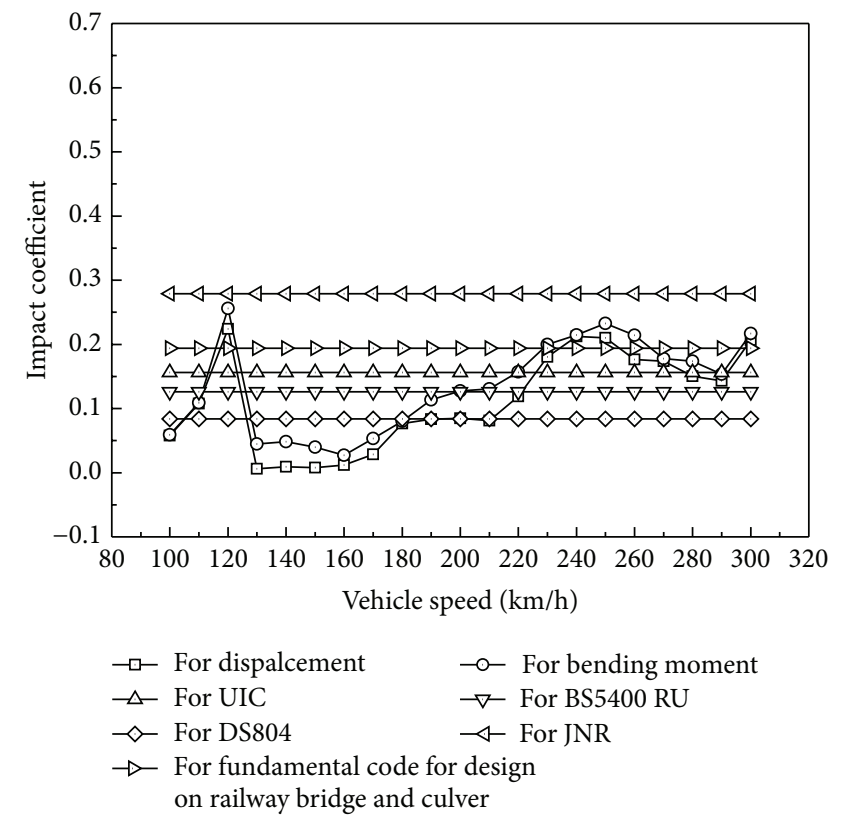

FIGURE 7: Comparison between values from BANSYS and values calculated by code formulas.

\section{Analysis of Impact Coefficient for Long-Span Cable-Stayed Bridge}

To study impact coefficient of Hanjiatuo Bridge, the analysis software BANSYS is employed to obtain the time history response curves of each component of Hanjiatuo Bridge under static and dynamic traffic loads.

However, in spite of the fact that the impact formulas presented in the existing codes only suit the middle and small span bridges, these formulas are also applied to the design of long-span bridges, which may lead to underestimating the impact coefficients. The impact coefficient of Hanjiatuo Bridge is 0.05 based on Fundamental Code for Design on Railway Bridge and Culvert [30].

3.1. Impact Coefficient for Displacement of Main Girder. $\mathrm{CRH} 2$ vehicles are passing through the bridge at the speeds of $160 \mathrm{~km} / \mathrm{h}, 200 \mathrm{~km} / \mathrm{h}$, and $240 \mathrm{~km} / \mathrm{h}$. The impact coefficients for the vertical displacement of the whole main girder are displayed in Figure 8. In order to investigate the relationship between the vehicle speed and the impact coefficient for the main girder, the following vehicle speed range from $100 \mathrm{~km} / \mathrm{h}$ to $240 \mathrm{~km} / \mathrm{h}$ with an interval of $20 \mathrm{~km} / \mathrm{h}$ is studied. The impact coefficients for the vertical displacement of typical positions on each span at various velocities are shown in Figure 9. 


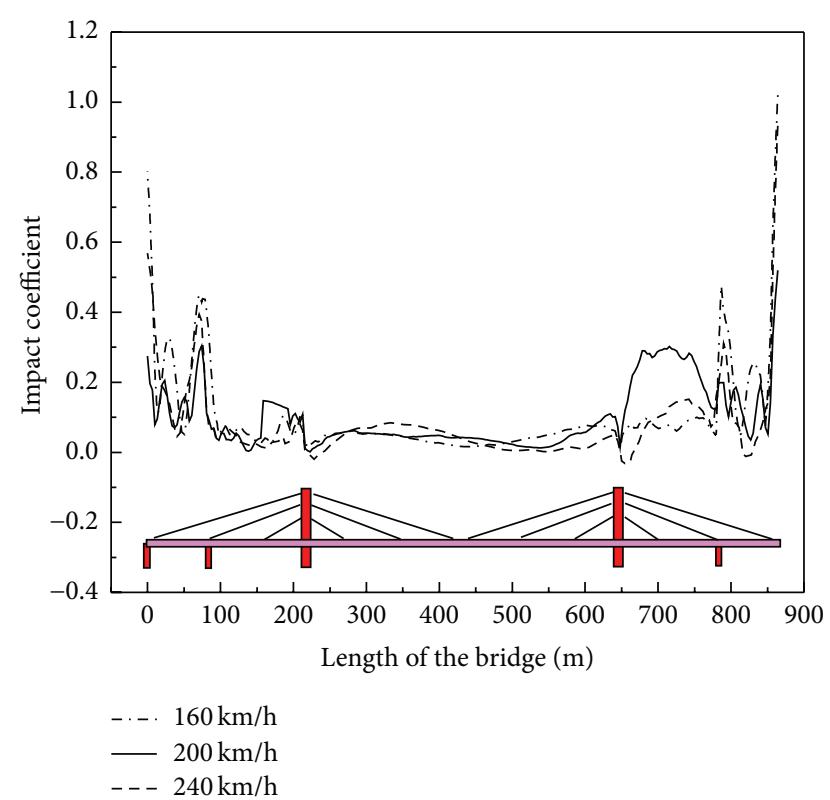

FIGURE 8: Impact coefficients for vertical displacement at different positions of main girder.

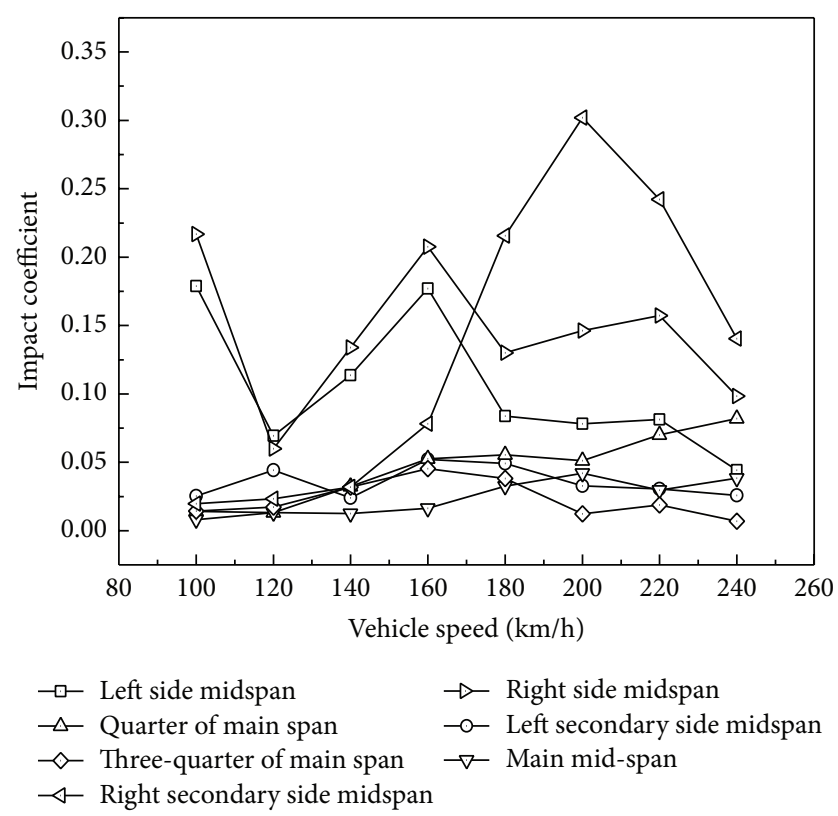

FIGURE 9: Impact coefficients for vertical displacement at typical positions of main girder.

It can be seen from Figures 8 and 9 that the long-span railway cable-stayed bridge has a lower natural frequency due to its flexible nature. Thus, resonance phenomenon occurs hardly in the range of the operational speed. Besides, the coupling effect between spans is strong. The variation of the impact coefficient is not obvious with the increase of the vehicle speed. On the whole, though the vertical displacements of bridge decks near the locations of piers and towers are small, the impact coefficients of the locations are greater than other locations. The impact coefficient for the vertical displacement of the main span is less than those of the other spans, and the impact coefficient is insensitive to the vehicle speed, which is due to the mitigation of impact effect resulting from the greater span length. The time histories for the vertical displacement of the right secondary side span at the speed of $200 \mathrm{~km} / \mathrm{h}$ are shown in Figure 10.

3.2. Impact Coefficient for Force of Cable. In order to study the impact coefficient for the force of cables, the stayed cables are divided into four cable areas in the longitudinal direction of the bridge, as shown in Figure 2. The stayed cables in each cable area are numbered from 1 to 14 with the increase of cable length. The vehicle speed range is from $100 \mathrm{~km} / \mathrm{h}$ to $240 \mathrm{~km} / \mathrm{h}$ with an interval of $20 \mathrm{~km} / \mathrm{h}$. The time histories for the force of cables under both static and dynamic vehicle loads are calculated by BANSYS, and the impact coefficients of each cable area at various vehicle speeds calculated from (1) are shown in Figure 11.

As shown in Figure 11, with the increase of the vehicle speed and the cable length, the variation of the impact coefficient for each cable area differs from each other. It should be specially noticed that the maximum value of the impact coefficient occurs at the first cable of number 4 cable area at the speed of $240 \mathrm{~km} / \mathrm{h}$, which approaches 1.11 . The impact coefficients of the shorter cables are sensitive to the vehicle speed; the impact coefficients for the force of the cables increase with the increasing vehicle speed.

When the static and dynamic vehicle loads act on the bridge at the speed of $200 \mathrm{~km} / \mathrm{h}$, the time histories for the force of three cables numbered 1, 5, and 14 at number 4 cable area are shown in Figures 12, 13, and 14.

3.3. Impact Coefficient for Force of Bearing. In order to study the impact coefficient for the force of bearing, the bridge piers are numbered from 1 to 5 as shown in Figure 2. Beam 4 element is employed to simulate bearing, and BANSYS is used to obtain the static and dynamic responses of bearing. When $\mathrm{CRH} 2$ vehicles pass through the bridge on the left line at the velocities of $160 \mathrm{~km} / \mathrm{h}, 200 \mathrm{~km} / \mathrm{h}$, and $240 \mathrm{~km} / \mathrm{h}$, the impact coefficients of the bearings computed are shown in Figure 15. When the vehicles pass through the bridge on the right line at the speed of $200 \mathrm{~km} / \mathrm{h}$, the impact coefficients are shown in Figure 15.

It can be seen from Figure 15 that the impact coefficients of the bearings do not augment with the increasing vehicle speed. Generally, the impact coefficients of tower bearings are smaller than those of the pier bearings, and the impact coefficients of the side pier bearings are greater than others. In contrast to the data shown in Figure 16, when vehicles pass through the bridge on the left line, the impact coefficients for the left bearings are less than those for the right bearings; otherwise, the impact coefficients for the right bearings are less than those for left bearing when vehicles pass through the bridge on the right line. The results show that when vehicles pass through the bridge on one side line, even if the forces for the bearings of the other side are less, the impact coefficients are greater. 


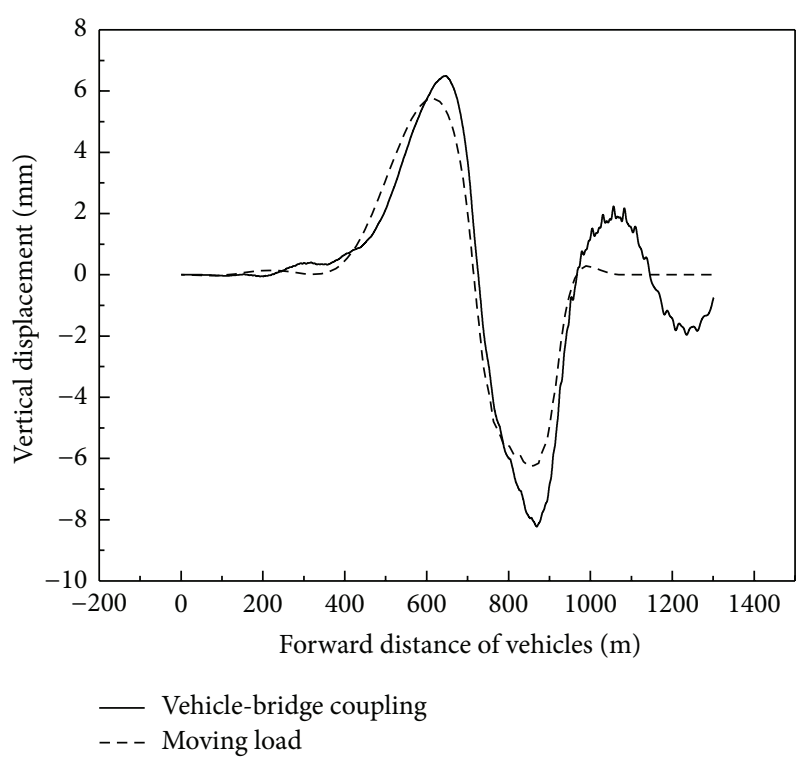

FIgURE 10: Time histories for vertical displacement of right secondary side span $(200 \mathrm{~km} / \mathrm{h})$.

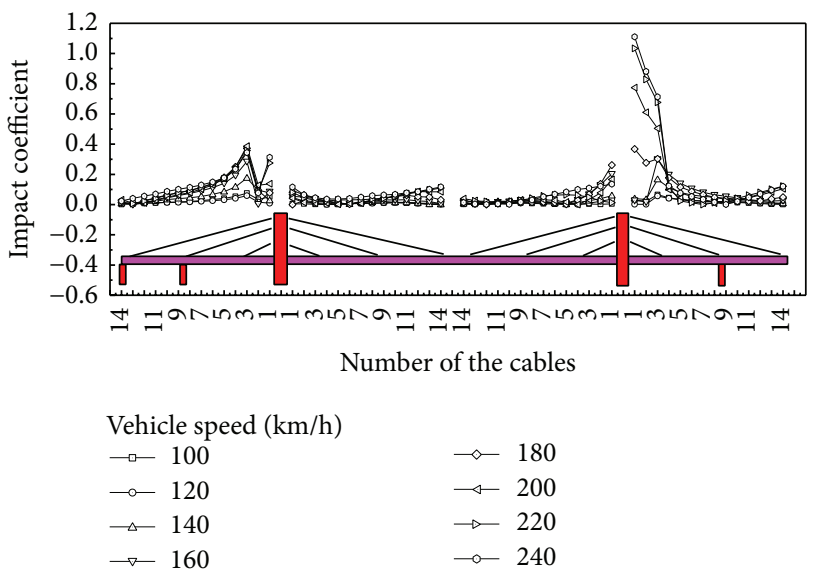

FIGURE 11: Impact coefficients for force of cable.

3.4. Impact Coefficient for Bending Moment of Bridge Tower. When $\mathrm{CRH} 2$ vehicles pass through the bridge with three various velocities, the impact coefficients for the bending moment of the bridge towers are shown in Figure 17. It can be seen that the stress distribution in the anchorage area of the cable-tower is complicated. The impact coefficients can be negative values, and the minimum value is -0.05 . The most obvious impact effect occurs at the element closest to the foundation of the bridge towers. The impact coefficient of number 4 tower at the speed of $240 \mathrm{~km} / \mathrm{h}$ can approach 1.08. At the vehicle speed of $200 \mathrm{~km} / \mathrm{h}$, the time history for the bending moment of the tower element between number 12 and number 13 cables belonging to number 3 tower is shown in Figure 18. It can be seen from Figures 17 and 18 that the impact effect for the upper part of bridge towers is limited.

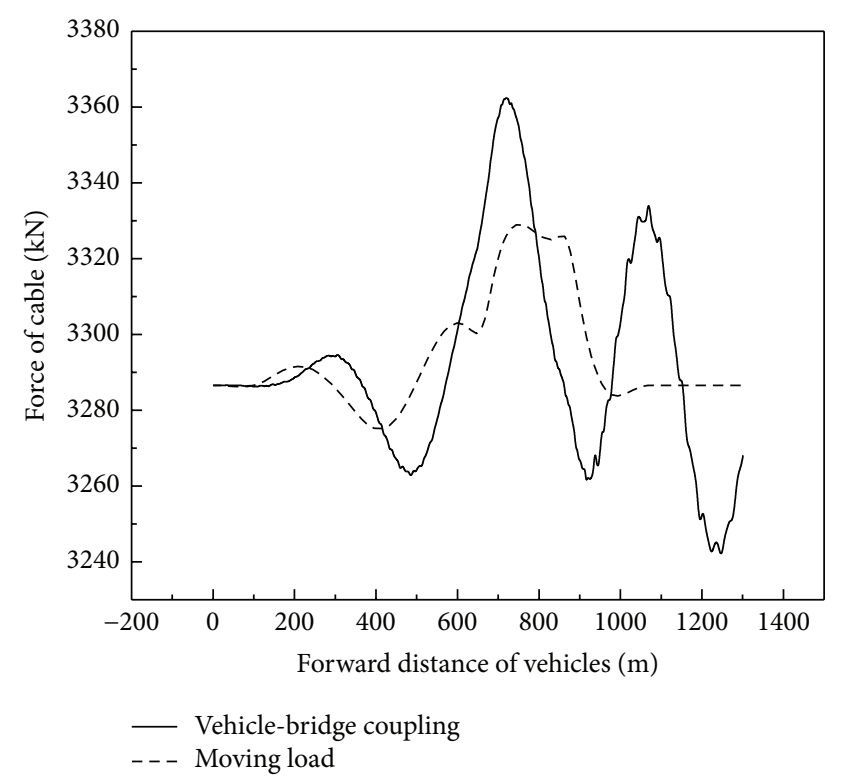

FIgURE 12: Time histories for force of number 1 cable.

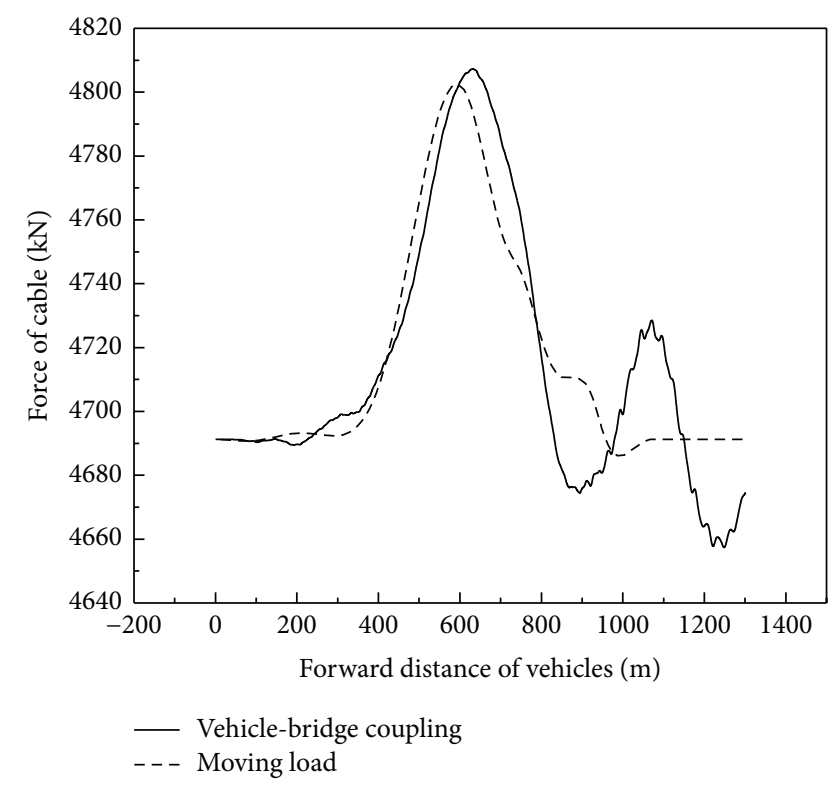

FIgURE 13: Time histories for force of number 5 cable.

\section{Conclusions}

(1) The vertical impact effect of a $32 \mathrm{~m}$ simply supported bridge is investigated systematically. The coupled vehiclebridge vibration system model is employed in the analysis, and the resonance speed computed by BANSYS is in good agreement with that calculated by the theoretical formula. The results show that it is feasible to study the impact coefficient based on the method of the coupled vehicle-bridge vibration.

(2) Different from a simply supported bridge, resonance phenomenon of a long-span railway cable-stayed bridge occurs hardly in the range of the operational speed. And 


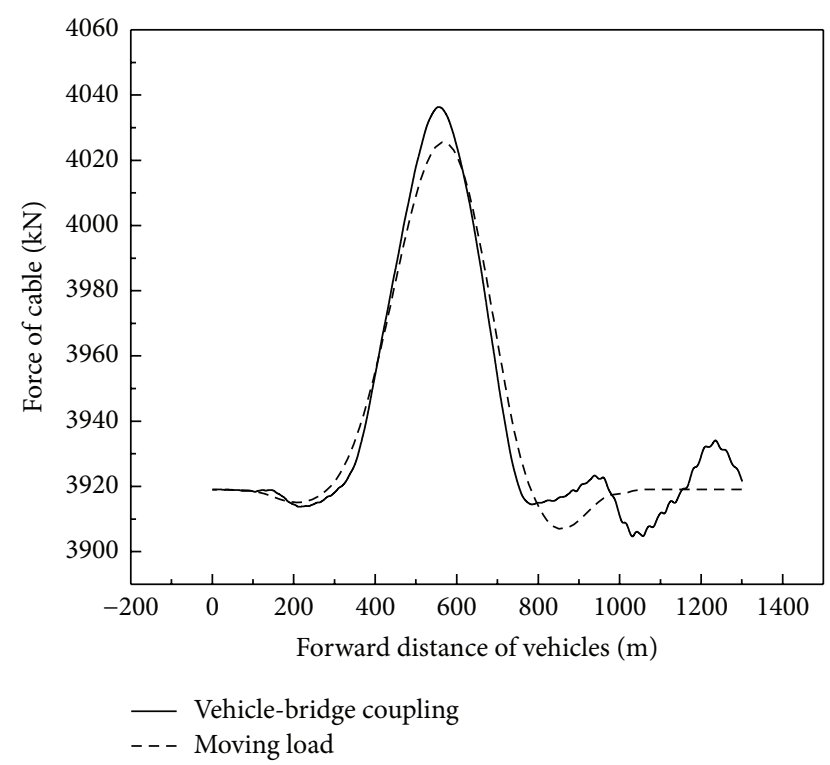

FIGURE 14: Time histories of force of number 14 cable.

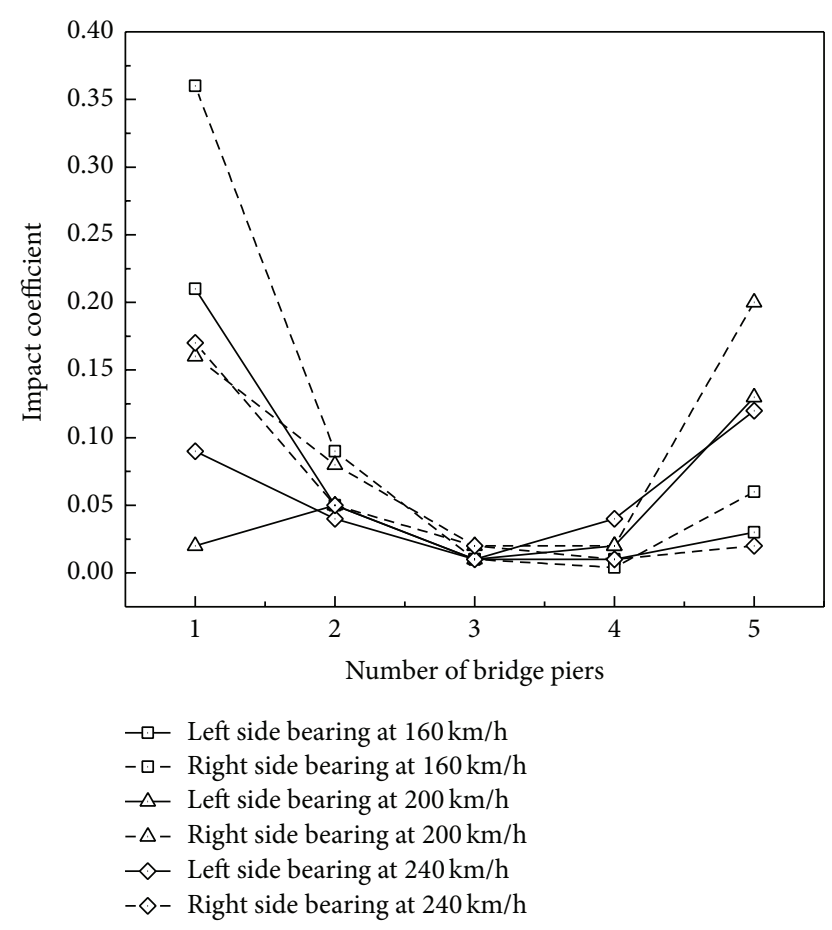

FIGURE 15: Train loading on the left line.

the variation of impact coefficient is not obvious with the increasing vehicle speed due to the strong coupling effects between spans. On the whole, the impact coefficient for the vertical displacement of the main span is less than that for the other spans. The impact coefficient of the right secondary side span is 0.30 while the impact coefficient for the main girder can approach 0.94 at the train leaving side.

(3) The impact coefficient for cable force increases with the increasing vehicle speed generally. The impact coefficients

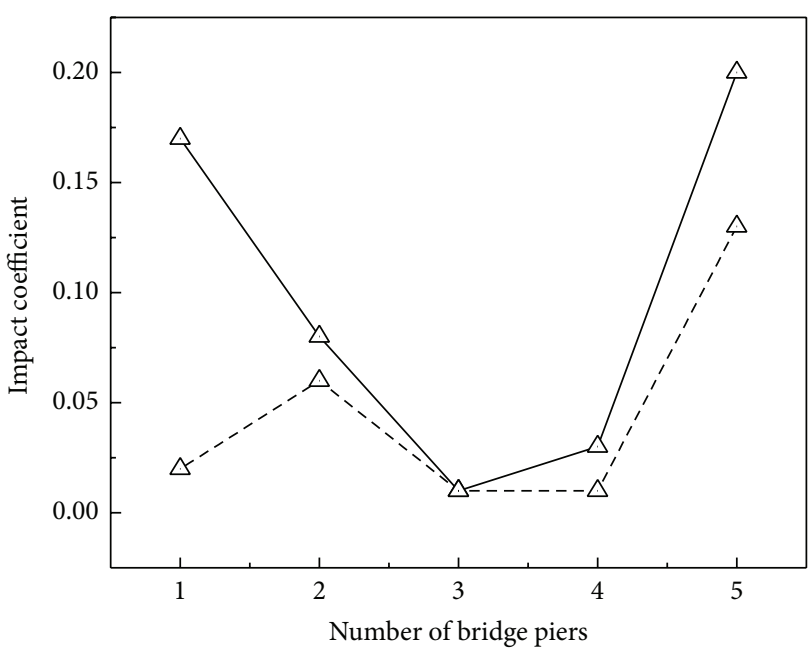

$\triangle$ Left side bearing

$-\triangle$ - Right side bearing

Figure 16: Train loading on the right line $(200 \mathrm{~km} / \mathrm{h})$.

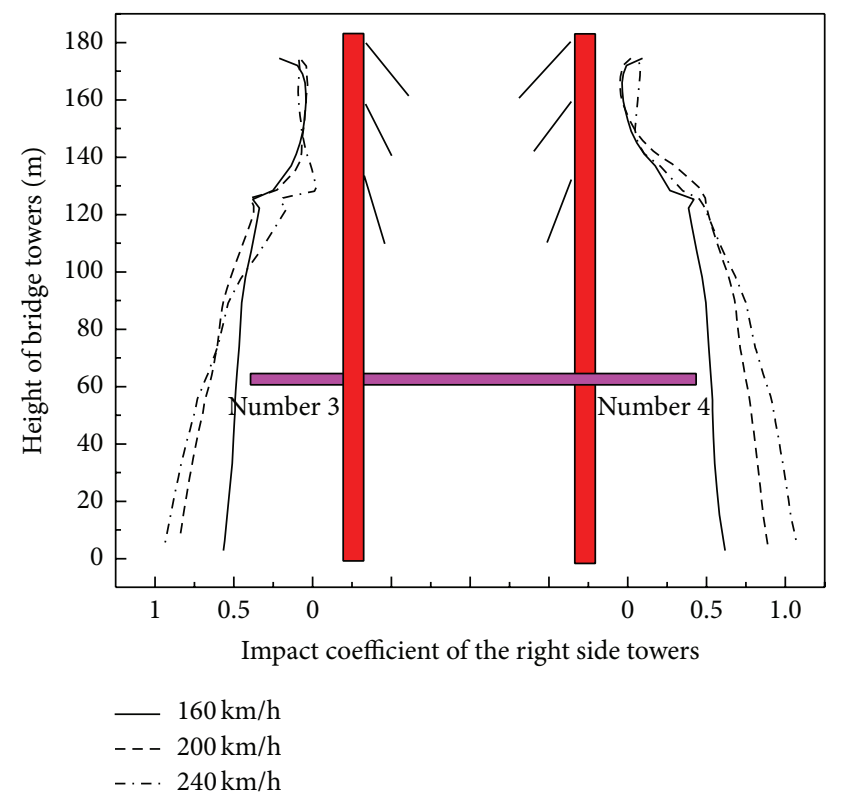

FIGURE 17: Impact coefficients for bending moment of bridge tower.

of shorter cables are sensitive to the vehicle speed, which can approach 1.11.

(4) The impact coefficient for the force on the bearings at the tower is small, while the impact coefficient for the force of the bearings at train entering side is significant, which can be 0.36 . Under the condition of unilateral loading on the bridge, the impact effect for the bearings of nonloading side is greater.

(5) On the whole, the closer the foundation of bridge towers, the larger the impact coefficient for the bending moment of the bridge towers, which can approach 1.08. In the anchorage area of the cable-tower, owing to the existence of cables, the stress distribution in this area is complicated and impact coefficients can be negative values. 


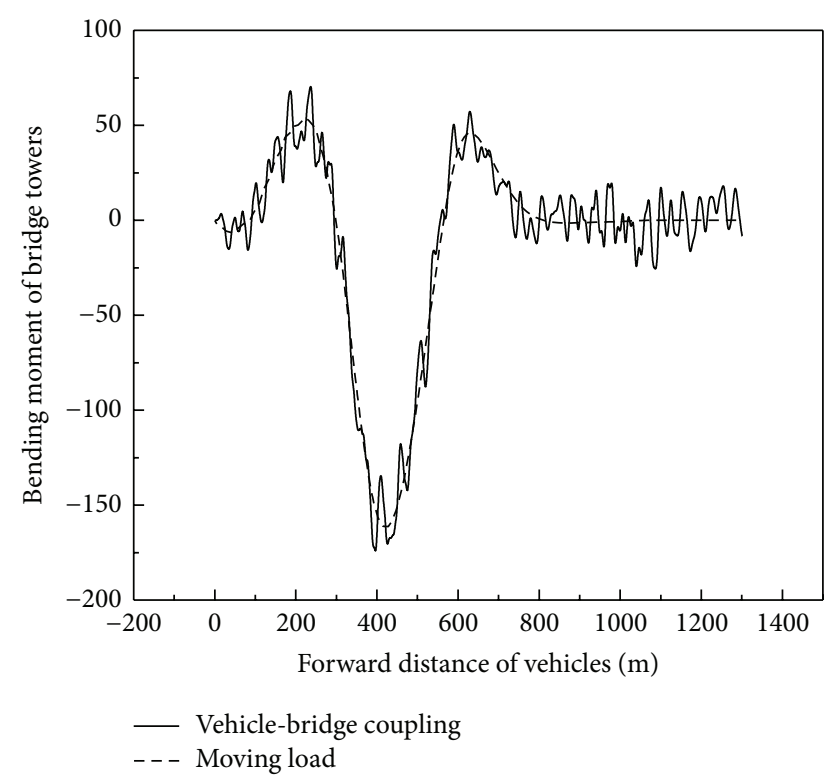

FIgURE 18: Time histories for bending moment of bridge tower.

In a word, different components of the long-span railway cable-stayed bridge have different impact coefficients. Each component also has different impact coefficients at different local positions. And numerical results are significantly different from the design code, except for that of main span, which approaches the design code. Impact coefficients of many positions are much larger than the value calculated by the code (0.05). The design code may focus on the impact coefficient of main span.

\section{Conflict of Interests}

The authors declare that there is no conflict of interests regarding the publication of this paper.

\section{Acknowledgments}

The authors are grateful to the financial supports from the National Natural Science Foundation of China (no. U1334201 and no. 51278434) and the Special Research Foundation of the National Railway Ministry of China (no. 2009G004-D).

\section{References}

[1] Y. Xia, B. Chen, X.-Q. Zhou, and Y.-L. Xu, "Field monitoring and numerical analysis of Tsing Ma suspension bridge temperature behavior," Structural Control and Health Monitoring, vol. 20, no. 4, pp. 560-575, 2013.

[2] E. S. Hwang and A. S. Nowak, "Simulation of dynamic load for bridges," Journal of Structural Engineering, vol. 117, no. 5, pp. 1413-1434, 1991.

[3] T.-H. Yi, H.-N. Li, and M. Gu, "Experimental assessment of high-rate GPS receivers for deformation monitoring of bridge," Measurement, vol. 46, no. 1, pp. 420-432, 2013.

[4] B. Chen, Z.-W. Chen, Y.-Z. Sun, and S.-L. Zhao, "Condition assessment on thermal effects of a suspension bridge based on SHM oriented model and data," Mathematical Problems in Engineering, vol. 2013, Article ID 256816, 18 pages, 2013.

[5] T.-H. Yi, H.-N. Li, and X.-D. Zhang, "Sensor placement on Canton Tower for health monitoring using asynchronous-climb monkey algorithm," Smart Materials and Structures, vol. 21, no. 12, Article ID 125023, 12 pages, 2012.

[6] M.-K. Song, H.-C. Noh, and C.-K. Choi, "A new threedimensional finite element analysis model of high-speed trainbridge interactions," Engineering Structures, vol. 25, no. 13, pp. 1611-1626, 2003.

[7] H. Xia, N. Zhang, and R. Gao, "Experimental analysis of railway bridge under high-speed trains," Journal of Sound and Vibration, vol. 282, no. 1-2, pp. 517-528, 2005.

[8] F. T. K. Au, J. J. Wang, and Y. K. Cheung, "Impact study of cable-stayed bridge under railway traffic using various models," Journal of Sound and Vibration, vol. 240, no. 3, pp. 447-465, 2001.

[9] F. T. K. Au, J. J. Wang, and Y. K. Cheung, "Impact study of cable-stayed railway bridges with random rail irregularities," Engineering Structures, vol. 24, no. 5, pp. 529-541, 2002.

[10] A. Matsuura, "Study of dynamic behaviors of bridge girders for high-speed railway," Journal of JSCE, vol. 256, no. 12, pp. 35-47, 1976.

[11] M. H. Bhatti, V. K. Garg, and K. H. Chu, "Dynamic interaction between freight train and steel bridge," Journal of Dynamic Systems, Measurement and Control, Transactions of the ASME, vol. 107, no. 1, pp. 60-66, 1985.

[12] X. D. Song, D. J. Wu, and Q. Li, "Dynamic impact analysis of double-tower cable-stayed maglev bridges using a simple model," Journal of Bridge Engineering, vol. 19, no. 1, pp. 34-43, 2014.

[13] Z. W. Chen, Y. L. Xu, Y. Xia, Q. Li, and K. Y. Wong, "Fatigue analysis of long-span suspension bridges under multiple loading: case study," Engineering Structures, vol. 33, no. 12, pp. 32463256, 2011.

[14] Z. W. Chen, Y. L. Xu, and X. M. Wang, "SHMS-based fatigue reliability analysis of multiloading suspension bridges," Journal of Structural Engineering, vol. 138, no. 3, pp. 299-307, 2012.

[15] A. Das, A. Dutta, and S. Talukdar, "Efficient dynamic analysis of cable-stayed bridges under vehicular movement using space and time adaptivity," Finite Elements in Analysis and Design, vol. 40, no. 4, pp. 407-424, 2004.

[16] D. Bruno, F. Greco, and P. Lonetti, "Dynamic impact analysis of long span cable-stayed bridges under moving loads," Engineering Structures, vol. 30, no. 4, pp. 1160-1177, 2008.

[17] T.-H. Yi, H.-N. Li, and M. Gu, "Optimal sensor placement for structural health monitoring based on multiple optimization strategies," The Structural Design of Tall and Special Buildings, vol. 20, no. 7, pp. 881-900, 2011.

[18] Y. Wang, Y. Pei, and Y. Zhao, "Vibration-based damage detection with structural modal characteristics," The Baltic Journal of Road and Bridge Engineering, vol. 3, no. 1, pp. 21-28, 2008.

[19] Y. L. Li, S. Z. Qiang, H. Liao, and Y. L. Xu, "Dynamics of windrail vehicle-bridge systems," Journal of Wind Engineering and Industrial Aerodynamics, vol. 93, no. 6, pp. 483-507, 2005.

[20] Y. L. Li, K. Zhao, and X. T. Cai, "Three-Orthogonal-Beam model for finite element simulation of bridge foundation stiffness," Bridge Construction, no. 6, pp. 17-20, 2010 (Chinese).

[21] L. Deng and C. S. Cai, "Development of dynamic impact factor for performance evaluation of existing multi-girder concrete bridges," Engineering Structures, vol. 32, no. 1, pp. 21-31, 2010. 
[22] J. D. Yau and Y. B. Yang, "Vertical accelerations of simple beams due to successive loads traveling at resonant speeds," Journal of Sound and Vibration, vol. 289, no. 1-2, pp. 210-228, 2006.

[23] Y. B. Yang, J. D. Yau, and L. C. Hsu, "Vibration of simple beams due to trains moving at high speeds," Engineering Structures, vol. 19, no. 11, pp. 936-943, 1997.

[24] H. Xia, N. Zhang, and W. W. Guo, "Analysis of resonance mechanism and conditions of train-bridge system," Journal of Sound and Vibration, vol. 297, no. 3-5, pp. 810-822, 2006.

[25] H. Xia, H. L. Li, W. W. Guo, and G. de Roeck, "Vibration resonance and cancellation of simply supported bridges under moving train loads," Journal of Engineering Mechanics, vol. 140, no. 5, pp. 1-11, 2014.

[26] UIC, "Loads to be considered in railway bridge design," UIC Code776-IR, France, 1994.

[27] BSI-BS5400, Steel, Concrete and Composite Bridge, 1978.

[28] DS804: Vorschrift fur Eisenbabn bracken and sontige Ingenieur bauwerke, Deutcsche Bundesbahn, 1993.

[29] Federal Railroad Administration, Track Safety Standards Compliance Manual, 2006.

[30] Ministry of Railyways of the People's Republic of China, "Fundamental code for design on railway bridge and culvert," Chinese Standard TB10002.1-2005, 2005, (Chinese). 

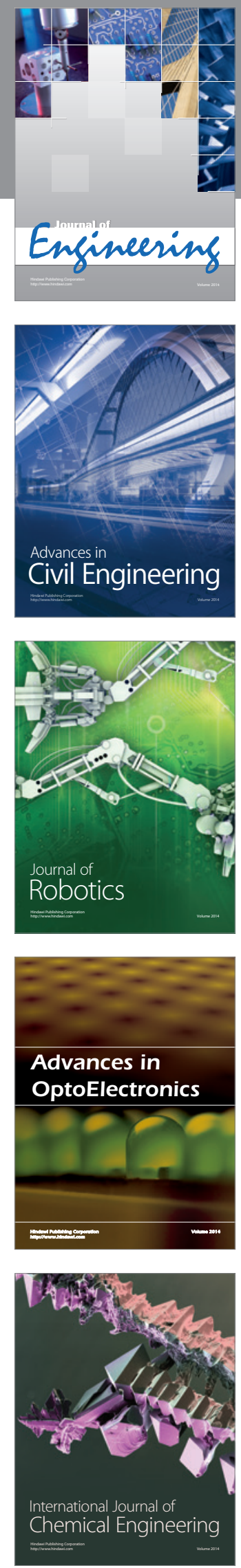

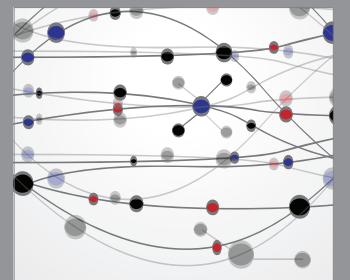

The Scientific World Journal
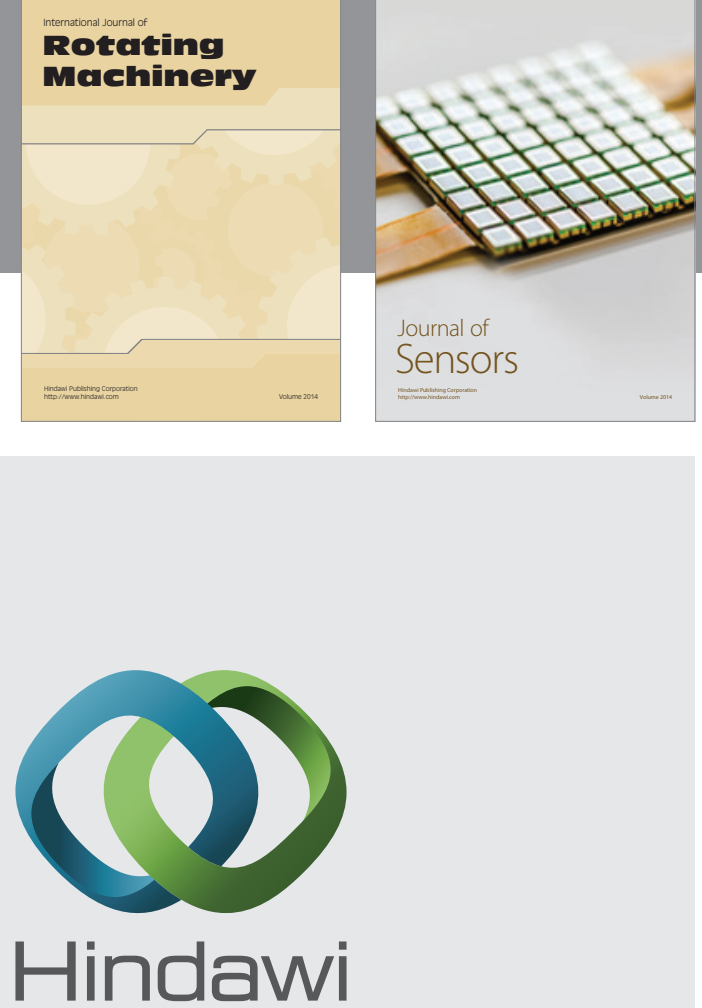

Submit your manuscripts at http://www.hindawi.com
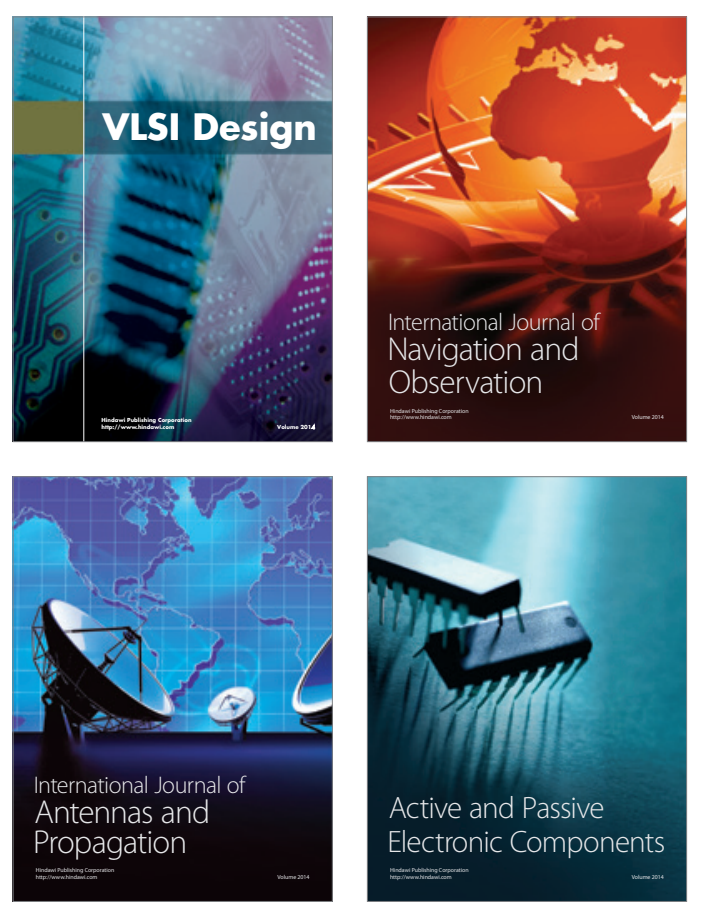
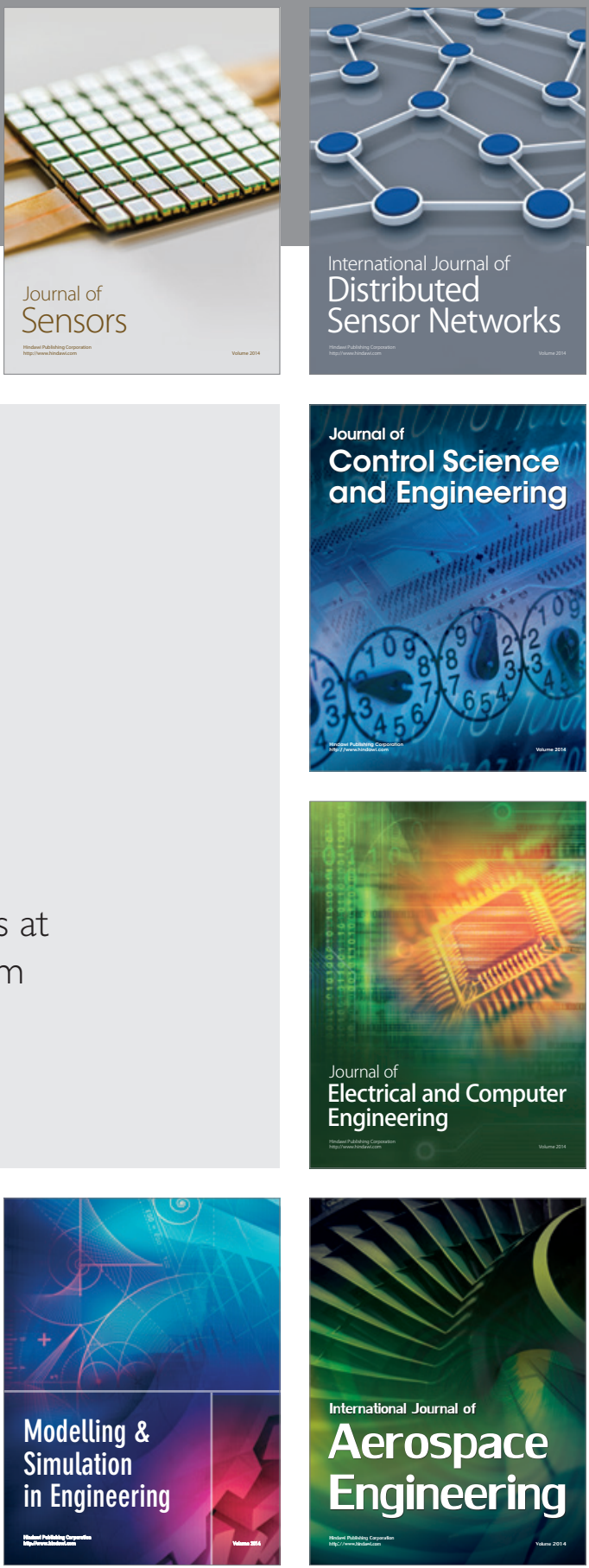

Journal of

Control Science

and Engineering
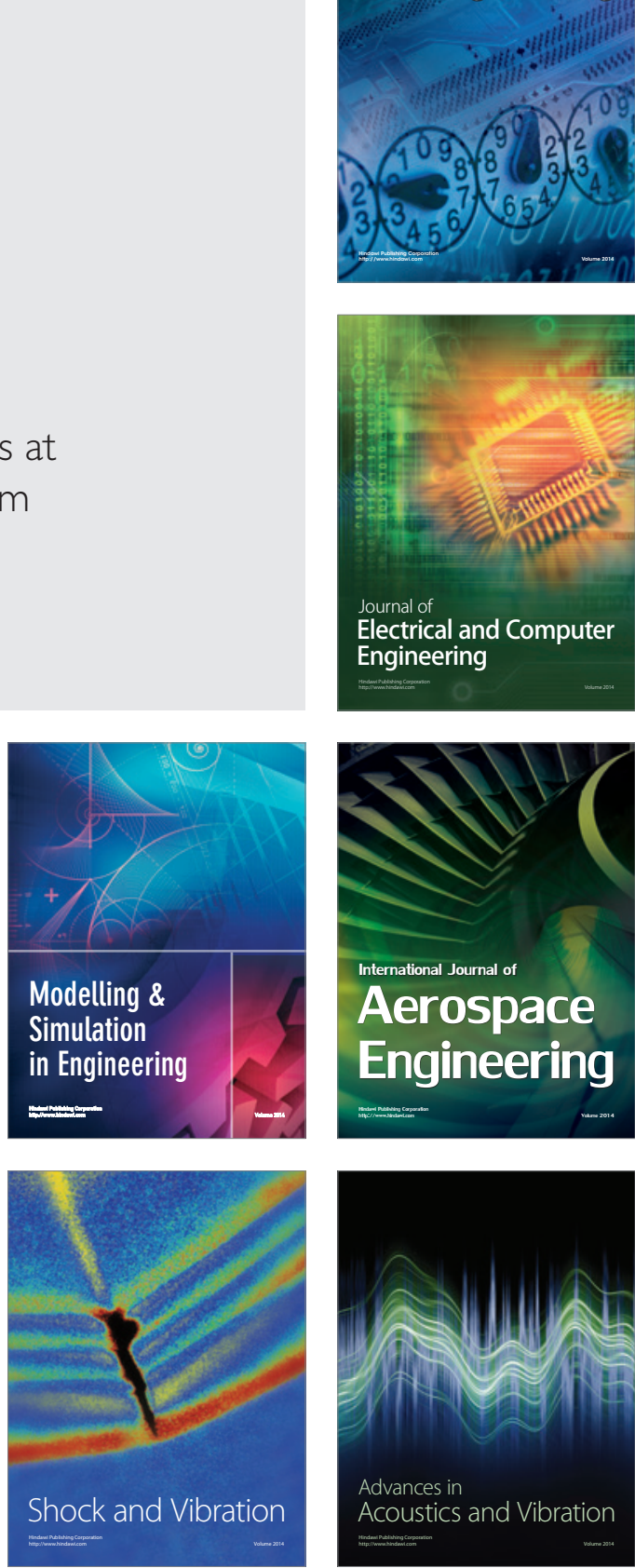